\title{
The Fuzzy Integrated Evaluation of Enterprise Information System Security Based on EC
}

\author{
Shaolong Zhang, Ning Zhou and Jiaxing Wu \\ Center for Studies of Information Resources, \\ Wuhan University, 430072 \\ zhangshaolong78@yahoo.com.cn
}

\begin{abstract}
As enterprises increase their electronic communication in business activities through network, the security of enterprise information system based on EC becomes crucial for enterprises. This paper proposes a fuzzy integrated security evaluation method based on man-computer combined data collection and fuzzy expert evaluation in Delphi method. The method could reduce the subjectivity of expert evaluation and alleviate the difficulty of data collection and makes possible a better combination of qualitative and quantitative evaluations. Firstly, the evaluation factor and hierarchy structure of security evaluation is constructed. Secondly, according to data collected and the evaluation comment of each expert, the subjection degree matrix is constructed. Finally, a new concept of "degree of assurance" is presented for the quantificational evaluation of enterprise information system security based on. In this paper the study of the case shows that the method can be easily used and its results conform to the actual situation.
\end{abstract}

\section{Introduction}

Electronic Commerce is the sharing of business information, maintaining business relationships, and conducting business transactions by means of telecommunications networks [1]. The explosion of the Internet as a ubiquitous business tool has propelled the hype over fruitful electronic commerce opportunities to new heights. But while modern networking technologies such as the Internet offer new tools for making the communication and sharing of information more efficient and faster than ever before, it can significantly increase exposure to information security risks. The risks of enterprise information system based on EC come from Internet and Intranet. Leakage and invalid access of information affect not only a single user or application,

Please use the following format when citing this chapter.

Zhang, S., Zhou, N., Wu, J., 2007, in IFIP International Federalion for Information Processing, Volume 251, Integration and Innovation Orient to F-Society Volumel, Wang, W. (Fds), (Boston: Springer), pp. 467-474. 
but may have disastrous consequences on the entire enterprise. The security evaluation of enterprise information system based on EC is a process in which the risk factors of the system are analyzed and explained. The basic goal of the security evaluation is to control the risk in acceptability.

By the reason of the uncertainty of the evaluation factor, the fuzzy logic method is used [2]. In this paper an improved fuzzy method is proposed to solve the security evaluation. The rest of this paper is organized as follows. In section 2 , an evaluation model is given for security evaluation. In section 3 , a case is put forward to illustrate our method. Finally, conclusions are drawn in Section 4.

\section{Construction of security evaluation model}

In the evaluation of enterprise information security based on EC, we face problems such as the complication of security factors, limited history statistical data and difficulty of data collection. There is no single method to solve these problems. We need an integrated evaluation method which comprises expert evaluation, statistical information and compute technology. To construct security evaluation model, firstly evaluation factors are recognized, then data is collected through man-computer method, at last based on fuzzy subjection theory and Delphi method qualitative evaluation is transferred to quantitative evaluation.

\subsection{The recognition of security evaluation factors}

Before the evaluation of security, we need a investigation on security factors. Usually system security is evaluated from three aspects which are strategy, management and technology. Strategy refers strategic status and strategic decision of information system security in the enterprise. Management includes organizations and regulations to the information system security and supervision on relative people and materials. Technology refers all kinds of security technologies. But under the EC environment human is to be interactive with enterprise information system based on network, referred with the systematic methodology of "Wuli-Shili-Renli (WSR)"[3], human is the key factor to the enterprise information security. Good guidance and access control to the web users and skills of network administrator are important to security of EC. Thus when we give the recognition of security evaluation factors, human is recognized as one of the top level factors as well as strategy, management, technology which sub-factors are also recognized based on.

\subsection{Man-computer combined data collection}

Applied with IT technology, most security data could be automatically collected. These technologies include computer log system, real-time scan tools and automatic audit system and so on. Using computer technology can bring benefits. Firstly it could reduce the subjectivity of expert evaluation and make the evaluation method more scientific and objective. Secondly it alleviates the human workload in data 
collection which not only cuts down the cost of human labor but also improves the veracity and the coverage of data collection. Some evaluation factors such as access control management and network management could be directly counted and evaluated based on automatically colleted data.

On the occasions that data could not be automatically collected by computer such as situations about training and security rules, questionnaire survey and On-the-spot investigation also could be applied.

\subsection{Expert evaluation in Delphi method}

The objective of most Delphi applications is the reliable and creative exploration of ideas or the production of suitable information for decision making. The Delphi Method is based on a structured process for collecting and distilling knowledge from a group of experts by means of a series of questionnaires interspersed with controlled opinion feedback (Adler and Ziglio, 1996). According to Helmer (1977) Delphi represents a useful communication device among a group of experts and thus facilitates the formation of a group judgment [4].

Based on data colleted experts make evaluations relying on their individual competence and are subjective, Delphi method is utilized to adjust the fuzzy evaluation of each expert to achieve the consensus condition of the all experts consistent.

Flowchart for the Delphi Method follows as [5]:

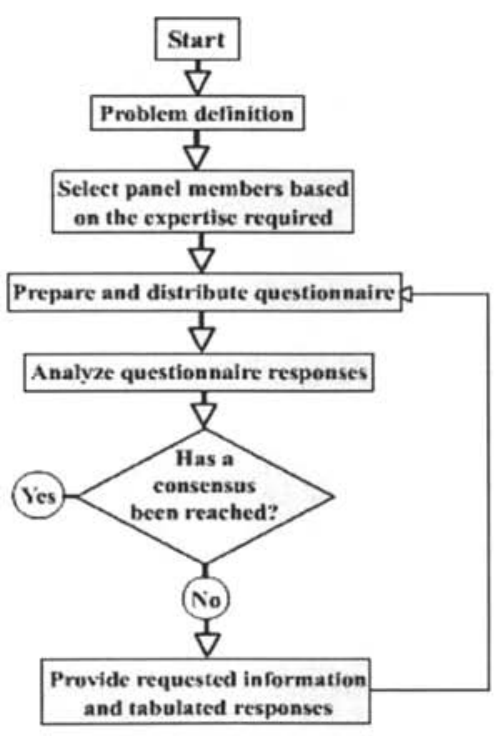

Figure 1. Flowchart of Delphi Method 


\subsection{Integrated Fuzzy Evaluation}

The major steps of evaluation are as the following.

Stepl. Construct the hierarchical structure. The top layer is the focus of the goal, and the bottom level, consists of the alternatives under evaluation. The factors and any sub-factors used to make the decision comprise the middle levels [6]. The factors is divided into $s$ subsets which defined as $Y_{1}, Y_{2} \ldots Y_{S}\left(Y_{i} \cup Y_{j}=\phi(1 \leq i, j \leq s \quad i \neq j)\right)$. Each subset $Y_{i}$ is constructed by the factors in the next level denoted as $X_{i n}$, so the characteristic vector of each subset $Y_{i}$ is presented by the expression.

$$
Y_{i}=\left(X_{i 1}, X_{i 2}, \ldots, X_{i n}\right)
$$

Step2. Construct the judge set. The expert group which is composed of information system experts, enterprise manager and end users provides all the judgements of the set. Suppose the judge set has $m$ judgements, judge set $V$ is $V=\{V$ $\left.{ }_{1}, \mathrm{~V}_{2}, \ldots, \mathrm{V}_{\mathrm{m}}\right\}$.

Step3. Build fuzzy evaluation matrix. We can construct the fuzzy reflection $\mathrm{f}: \mathrm{Y}$ $\rightarrow F(V), Y$ is the whole of the factor set and $F(V)$ is the whole of the fuzzy set in $V$. The reflection $f$ means the degree of the support from the factor $Y_{i}$ to each judgement in the judge set [7]. The subjection vector of $Y_{i}$ to the judge set $V$ is $R_{i}=\left(r_{i j, k}\right)$ $n^{*} m(i=1,2, \ldots, s ; j=1,2, \ldots, n ; k=1,2, \ldots, m) . r_{i j, k}$ is the subjection degree of factor $x_{i j}$ to judgement $V_{k}$ given by expert which meets the requirements that the range of the value is $[0,1]$ and the count of values $\sum r_{i j}=1$.

Step4. Estimate the normalized priority weights. The priority weight vector of subsets is presented by the expression.

$$
A_{i}=\left(a_{i 1}, a_{12}, \ldots, a_{i n}\right) \text {, and } a_{i j}=1
$$

There are several methods such as AHP method and dual correlation function method to give priority weights. According to the particularity of enterprise information system security based on EC, in the case of this paper the weights are given by experts in Delphi method.

Step5. Calculate evaluation vector $B_{i}$ corresponding to subset $Y_{i}$. The calculation formula is

$$
B_{i}=A_{i} \cdot R_{i}=\left(b_{i 1}, b_{i 2}, \ldots, b_{i m}\right) \text {. }
$$

Weighted average means is applied to each vector $B_{i}$ to take valuable information of each evaluation into account. The expression is

$$
\mathrm{b}_{\mathrm{ik}}=\sum_{j=1}^{n} \quad \mathrm{a}_{\mathrm{ij}} \mathrm{r}_{\mathrm{ij}, \mathrm{k}}(\mathrm{k}=1,2, \ldots, \mathrm{m}) .
$$

Step6. Calculate the whole fuzzy evaluation. Each subset $Y_{i}$ is treated as a single element and $B_{i}$ is treated as evaluation vector of $Y_{i}$, The fuzzy evaluation matrix is 


$$
\mathrm{B}=\left(\begin{array}{c}
B_{1} \\
B_{2} \\
\cdots \\
B s
\end{array}\right)=
$$

Referred with priority weight vector of each subset $A$ which is represented as $A=$ $\left(\mathrm{a}_{1}, \mathrm{a}_{2}, \ldots, \mathrm{a}_{\mathrm{s}}\right)$ and $\sum_{i=1}^{s} \mathrm{a}_{i}=1$, the final evaluation $\mathrm{T}=\mathrm{A} \cdot \mathrm{B}=\left(\mathrm{t}_{1}, \mathrm{t}_{2}, \ldots, \mathrm{t}_{\mathrm{m}}\right)$ is calculated.

\subsection{Quantificational evaluation result of security}

It is difficult to give quantificational result to final evaluation. To achieve a quantificational evaluation result, the degree of assurance is introduced which is denoted as $\mathrm{G}$.

To calculate $G$, judge set $V$ should be quantified first. For example, judgement "Very High" would be evaluated as 100 . Quantified judge set $V^{\prime}=\left\{V_{1}^{\prime}, V_{2}^{\prime}, \ldots, V_{m}^{\prime}\right\}$.

$$
\mathrm{G}=\sum_{i=1}^{m} \quad \mathrm{t}_{\mathrm{i}} \mathrm{V}_{\mathrm{i}}^{\prime}
$$

\section{The case}

In this case the hierarchy structure is constructed; evaluation factors are divided into four subsets which are Strategy, Management, Technology and Human. Sub-factors and the alternatives under evaluation are shown as Tables 1 (priority weight in the brackets).

The judge set $\mathrm{V}$ is $\mathrm{V}=\left\{\mathrm{V}_{1}, \mathrm{~V}_{2}, \mathrm{~V}_{3}, \mathrm{~V}_{4}, \mathrm{~V}_{5}\right\}$ which shows the risk probability level. Its meaning is " $V_{1}$ Very High, $V_{2}$ High, $V_{3}$ Medium, $V_{4}$ Low , $V_{5}$ Very Low".

\begin{tabular}{|c|c|c|c|}
\hline $\mathrm{NO}$ & Top factors & Sub-factors & Alternatives \\
\hline \multirow{2}{*}{1} & \multirow[t]{2}{*}{$\begin{array}{c}\text { Strategy } \\
(0.15)\end{array}$} & \multirow{2}{*}{$\begin{array}{l}\text { Strategy status of IT department } \\
\qquad(0.5)\end{array}$} & $\begin{array}{l}\text { Information literacy of } \\
\text { enterprise leader }\end{array}$ \\
\hline & & & $\begin{array}{l}\text { Investment of IT } \\
\text { construction }\end{array}$ \\
\hline
\end{tabular}

Table 1. Evaluation factors of the case 
472 The Fuzzy Integrated Evaluation of Enterprise Information System Security Based on $\mathrm{EC}$

\begin{tabular}{|c|c|c|c|}
\hline \multirow{2}{*}{2} & & \multirow{2}{*}{$\begin{array}{c}\text { Security information system } \\
\text { construction plan and budget }(0.5)\end{array}$} & $\begin{array}{c}\text { Long-term plan of } \\
\text { information system } \\
\text { construction }\end{array}$ \\
\hline & & & $\begin{array}{c}\text { Investment of } \\
\text { information system } \\
\text { construction } \\
\end{array}$ \\
\hline \multirow[b]{2}{*}{3} & \multirow{9}{*}{$\begin{array}{c}\text { Management } \\
(0.3)\end{array}$} & \multirow[b]{2}{*}{ Laws and regulations $(0.2)$} & $\begin{array}{l}\text { Protection from laws } \\
\text { and regulations }\end{array}$ \\
\hline & & & $\begin{array}{l}\quad \text { comprehensive } \\
\text { rules and regulations } \\
\text { within enterprise }\end{array}$ \\
\hline \multirow{3}{*}{4} & & \multirow{3}{*}{ Human management $(0.3)$} & $\begin{array}{c}\text { qualifications } \\
\text { examination of system } \\
\text { administrator and operators }\end{array}$ \\
\hline & & & on-the-job training \\
\hline & & & division of privileges \\
\hline \multirow[b]{2}{*}{5} & & \multirow[b]{2}{*}{ Environment management $(0.2)$} & $\begin{array}{l}\text { firewall and router } \\
\text { setting }\end{array}$ \\
\hline & & & $\begin{array}{c}\text { temperature and } \\
\text { humidity control, power } \\
\text { management, wiring } \\
\text { management }\end{array}$ \\
\hline \multirow{2}{*}{6} & & \multirow{2}{*}{ Risk management $(0.3)$} & $\begin{array}{c}\text { establishment of } \\
\text { information system backup } \\
\text { mechanism }\end{array}$ \\
\hline & & & $\begin{array}{c}\text { preparation of } \\
\text { emergency predetermined } \\
\text { plan }\end{array}$ \\
\hline \multirow{4}{*}{10} & \multirow[t]{8}{*}{$\begin{array}{c}\text { Technology } \\
(0.4)\end{array}$} & \multirow{4}{*}{ Operating system $(0.2)$} & $\begin{array}{l}\text { Legal operating system } \\
\text { software }\end{array}$ \\
\hline & & & system patch update \\
\hline & & & $\begin{array}{r}\text { password protection and } \\
\text { logon privilege management }\end{array}$ \\
\hline & & & anti-virus protection \\
\hline \multirow{3}{*}{11} & & \multirow{3}{*}{ Safety in transmission $(0.3)$} & $\begin{array}{l}\text { encryption in IP } \\
\text { package }\end{array}$ \\
\hline & & & $\begin{array}{l}\text { reliable transmission in } \\
\text { VPN }\end{array}$ \\
\hline & & & $\begin{array}{l}\text { integration in data } \\
\text { transmission }\end{array}$ \\
\hline 12 & & Network access control $(0.1)$ & $\begin{array}{l}\text { access control of web } \\
\text { users }\end{array}$ \\
\hline
\end{tabular}




\begin{tabular}{|c|c|c|c|}
\hline & & & $\begin{array}{c}\text { adoption of security } \\
\text { authentication protocol such } \\
\text { as SSL and SET }\end{array}$ \\
\hline 13 & & Security audit system $(0.2)$ & $\begin{array}{c}\text { Tracing and collecting } \\
\text { audit data including system } \\
\log \text {, firewall log }\end{array}$ \\
\hline 14 & & $\begin{array}{l}\text { Encryption key management } \\
\qquad(0.2)\end{array}$ & $\begin{array}{c}\text { creation and } \\
\text { management of encryption } \\
\text { key based on absolutely safe } \\
\text { regulations }\end{array}$ \\
\hline \multirow{2}{*}{15} & \multirow{3}{*}{$\begin{array}{l}\text { Human } \\
(0.15)\end{array}$} & \multirow{2}{*}{$\begin{array}{l}\text { Human resource } \\
\text { management( } 0.5)\end{array}$} & $\begin{array}{l}\text { Employment of } \\
\text { important people }\end{array}$ \\
\hline & & & $\begin{array}{l}\text { reservation of technical } \\
\text { personnel }\end{array}$ \\
\hline 16 & & Human education $(0.5)$ & $\begin{array}{l}\text { enterprise interior } \\
\text { training mechanism }\end{array}$ \\
\hline
\end{tabular}

The experts make judgements of the subjection to the judge set V. Evaluation matrixes R1, R2, R3 and R4 are:

$$
\begin{aligned}
& R_{1}=\left(\begin{array}{lllll}
0.25 & 0.35 & 0.30 & 0.10 & 0.00 \\
0.35 & 0.35 & 0.20 & 0.10 & 0.00
\end{array}\right) \\
& R_{2}=\left(\begin{array}{lllll}
0.35 & 0.35 & 0.20 & 0.10 & 0.00 \\
0.35 & 0.35 & 0.20 & 0.10 & 0.00 \\
0.50 & 0.30 & 0.10 & 0.10 & 0.00 \\
0.10 & 0.20 & 0.55 & 0.10 & 0.05
\end{array}\right) \\
& R_{3}=\left(\begin{array}{lllll}
0.15 & 0.25 & 0.25 & 0.15 & 0.20 \\
0.45 & 0.30 & 0.25 & 0.00 & 0.00 \\
0.20 & 0.25 & 0.35 & 0.10 & 0.10 \\
0.20 & 0.20 & 0.25 & 0.25 & 0.10 \\
0.50 & 0.40 & 0.10 & 0.00 & 0.00
\end{array}\right) \\
& R_{4}=\left(\begin{array}{lllll}
0.45 & 0.30 & 0.15 & 0.10 & 0.00 \\
0.35 & 0.25 & 0.30 & 0.10 & 0.00
\end{array}\right)
\end{aligned}
$$

Calculate evaluation vector $\mathrm{Bi}$

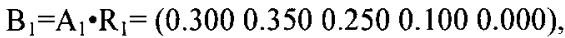

$$
\begin{aligned}
& \mathrm{B}_{2}=\mathrm{A}_{2} \cdot \mathrm{R}_{2}=\left(\begin{array}{l}
0.3050 .2950 .2850 .1000 .015
\end{array}\right) \text {, } \\
& \mathrm{B}_{3}=\mathrm{A}_{3} \cdot \mathrm{R}_{3}=\left(\begin{array}{ll}
0.3250 .2850 .2300 .0900 .070
\end{array}\right) \text {, } \\
& \mathrm{B}_{4}=\mathrm{A}_{4} \cdot \mathrm{R}_{4}=\left(\begin{array}{lll}
0.400 & 0.2750 .2250 .100 & 0.000
\end{array}\right) \text {, }
\end{aligned}
$$

The final evaluation $T$ is also calculated as

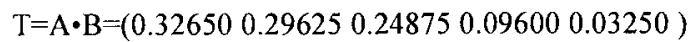

Referred with the definition in section 2.5 , judge set $V$ is quantified as $V^{\prime}=\{100$, $80,60,40,20\}$. 
The degree of assurance $\mathrm{G}=\mathrm{T} \cdot \mathrm{V}^{\prime}=75.765$.

Suppose it defines the value $\mathrm{G}$ from 0 to 30 to be very dangerous, from 31 to 60 to be unsafe, from 61 to 70 to be normally safe, from 71 to 85 to be well guarded, from 86 to 100 to be perfect, The security in this case is normally safe but it need improves and reinforced.

\section{Conclusion}

In this paper, an integrated evaluation method of enterprise information system security based on EC is presented. Each risk factor is estimated by the experts and for calculating the quantificational security evaluation of the whole system, the degree of assurance is introduced. The case result in this paper shows that the proposed method is scientific and tally with the actual situation.

\section{Acknowledgements}

This research is supported by the Social Science Foundation of Education Department of China under Grant No.05JZD00024.

\section{Reference}

1. V. Zwass, "Electronic Commerce: Structure and Issues", International Journal of Electronic Commerce, Vol. 1, Nr. 1, pp.3-23, 1996.

2. J. H. M. That and V. Carr, "A proposal for construction project risk evaluation using fuzzy logic" , Construction Management and Economics, no.18, pp.491-500, 2000.

3.Xu Xiulin, Hu Kejin, Research of Enterprise Information Security Based on WSR Method, Network and Computer Security in China, no.2, pp.13-16, 2006.

4. The Delphi Method Definition and Historical Background 2007, http://www. iit.edu it/delphi.html, 2007-3-20.

5. The Delphi Method 2007, http://www.ryerson.ca/ mjoppe/ResearchProcess 841 TheDelphiMethod.htm, 2007-3-20.

6. M. A. Mustafa and J. Bahar, "Project risk assessment using the analytic hierarchy process", IEEE Transactions on Engineering Management, vol.38, no.1, pp.46-52, 1991. 7. D. M. Zhao , "Comprehensive Risk Assessment of the Network Security", Computer Science, vol.31, no.7, pp66-69, 2004. 